\title{
Community Participation in the Community Nursery Program in Manokwari Regency, West Papua Province
}

\author{
Jacob Manusawai ${ }^{1}$, Eva Herlina ${ }^{2}$, Ihwan Tjolli ${ }^{1}$, Rina N. Jowei ${ }^{1} \&$ Anton S. Sinery ${ }^{1}$ \\ ${ }^{1}$ Environmental Research Centar of Papua University, Indonesia \\ ${ }^{2}$ Protected Forest and Watershed Management Institution of Remu Ransiki, West Papua, Indonesia \\ Correspondence: Anton S. Sinery, Environmental Research Center of Papua University, AmbanManokwari \\ 98313, Indonesia. Tel: 085-244-308-802. E-mail: anton_sineri@yahoo.com
}

Received: November 9, 2019

Accepted: December 6, 2019

Online Published: January 7, 2020

doi:10.5539/eer.v10n1p1

URL: https://doi.org/10.5539/eer.v10n1p1

\begin{abstract}
The purpose of this study is to determine and analyze the degree of community participation in the Community Nursery (Kebun Bibit Rakyat-KBR) program in Wasai Village and Arfai I Village, the district of South Manokwari, in the Manokwari Regency. Also this study aims to identify the factors that influence the level of community participation, and then formulates several management efforts to improve community participation in the program. The result found that communities that get involved in the KBR program are community groups of various types of professions, ethnicities and genders. The level of community participation in the KBR program is included in the high category for the whole set of activities in the KBR. However, for activities related to technical knowledge on planting and administration, community participation was still low. The significant factor affects the successful implementation of the KBR program was the direct involvement of community leaders. The support and involvement of community leaders played an important role in motivating the community to actively age in the KBR program. In addition, financial benefits of the program for individuals and village communities became the other determining factor that motivated the community to actively join in the KBR program. The alternative formulation offered in the early preparation of KBR activities was the program socialization. The early information has to be designed more effectively, so that the community is able to understand the procedures for implementing the KBR program, especially activities related to technical knowledge. Moreover, the involvement of other community leaders was a concern for the implementation of the KBR program since they were considered as the role models of social communities. Finally, collaborative programs with multi-stakeholders would be a solution to provide multiple benefits for the community as part of regional and national development goals.
\end{abstract}

Keywords: participation, communitynursery, local communities

\section{Introduction}

The community nursery program (KBR) is one of the government's programs that facilitate in supplying forest plant seeds and multi purpose tree species (MPTS), which the process was carried out independently by community' group. The target of community nursery program is to rehabilitate and plant critical land, vacant land and unproductive land as an effort to accelerate rehabilitation of degraded forest and land with the focus on priority disaster prone watersheds (Ministry of Environment and Forestry, 2016).

The community nursery development program based on the Minister of Environment and Forestry Regulation of the Republic of Indonesia Number P.49/MenLHK/Setjen/Das.2 /5/2016 concerning guidelines for implementing community nursery was one of the rehabitation forest and land programs aimed at restoring, improving and maintaining forest functions and land to increase the carrying capacity and productivity of the forest / land. Community participation in the implementation of the KBR program largely determines the success of the program, especially the production and planting of seedlings produced by the community nursery, therefore it is necessary to examine the degree of community participation in managing this program, as this is to be considered in formulating the upcoming KBR program.

The community nursery (KBR) program had been carried out in Manokwari Regency from 2010 to 2016. Wasai and Arfai I Villages were villages in South Manokwari District that implemented the KBR manufacturing 
program in 2016 and carried out planting of KBR seedlings in 2017. In the two villages there were 2 (two) community groups implementing the KBR program, accompanied by 1 (one) field assistant.

The implementation of this program involves community participation from planning, implementation of nursery making, planting and monitoring of evaluations. The entire KBR program should be carried out by the community and accompanied by a field facilitator, but to date the level of community participation in the implementation of the program was unknown.

The KBR program could be successful if it was supported by community participation from planning, implementation, monitoring and evaluation as well as planting KBR seedlings. The purpose of this activity was to improve the quality of the environment by providing adequate seedlings and their origins, increasing community participation in the implementation of activities, increasing community knowledge about seed making and planting techniques, increasing community awareness of planting culture to improve environmental quality and community welfare. This study aimed to determine community participation in the program of KBR in Wasai Village and Arfai I Village in South Manokwari District, Manokwari Regency.

\section{Method}

This research was conducted in 2 (two) villages, Wasai and Arfai, in Manokwari Regency. The study was started from September to October 2017. The tools and materials used in this study were GPS, cameras, tape recorders / cellphones, writing instruments, calculators, computers, questionnaires, maps and documents related to research. The method used in this research was descriptive method with observation and interview techniques. Descriptive method was intended to describe the condition of variables or research data in accordance with observations and interviews.

The variables observed in this study were divided in two variables, the main and supporting variables. The main variable consisted of six levels of community participation in the program to create a community nursery which included elements of the community who participated and unparticipated, community involvement in functions / roles (as planners, implementers or supervisors), and intensity of participation.

Community participation was measured based on the total score of questions. The questions related to participation in the planning stage, participation in the implementation phase, participation in the inspection stage of making KBR, participation in the preparation of planting plans, participation in the planting stage, participation in the evaluation stage. Participation questions at each stage of the activity ranged from 4-12 questions with an index score of 3 levels (high, medium and low). Scores for high, medium and low levels of participation at each stage of activities differ according to the number of questions at each stage. Furthermore, to determine the level of community participation in the overall program implementation could be determined based on the accumulation of the number of community participation in all stages of the activity (Sugiyono, 2014). The number of questions in all stages of the activity amounted to 36 questions these were divided into 3 index scores as follows 25-36 (high), 13-24 (medium/moderate) and 1-12 (low). The factors that determine community participation were identified ascounseling, type of work, involvement of community leaders and income. The factors were assessed based on the results of interviews with respondents expressed by the number of respondents (percentage).

Respondents used as samples were determined by "purposive sampling", namely determination of samples carried out intentionally, in accordance with community participation in the 2016 KBR program in 2 (two) community groups with a minimum number of 15 members, so that the number of respondents was 31 people. The sample respondents involved the village head and village officials, group facilitators, group leaders and all community group members involved in the program.

The data obtained were analyzed by tabulation and descriptive method through the following steps:

\section{1). Community Participation in the KBR Program}

a. Planning Stage Participation

Community participation at this stage included the socialization of the community nursery (KBR), the formation of community groups, preparation of activity proposals, preparation of proposals for group activities (RUKK) and employment contracts with the implementing parties. Participation scores used in this section consisted of high level of pertisiation (score 5), moderate (3-4) and low (1-2).

b. Participation in the KBR Program Implementation Stage

Participation in the implementation phase of the KBR program included the activities of making nursery facilities and infrastructure including nameplate, sowing beds, wean beds, fertilizers and insecticides, seed 
production and maintenance, seed or cuttings procurement, sowing, weaning, watering, fertilizing, fertilizing, cleaning grass / weeds / weeds, pest and disease management. The level of participation and scores on respondents consisted of high (9-12), moderate (5-8) and low (1-4).

\section{c. Participation Stage of Examination of the Results of Work Making KBR}

Activities at this stage included the inspection of work phase I, which was physical realization of at least $30 \%$ of available facilities and infrastructure. In this phase, generatis seeds had been sown on sowing beds or vegetative seedshad been planted into seed media in polybags. Phase II was a physical realization of a minimum of $60 \%$ of all generative and vegetative seeds in sufficient quantity and healthy and already in a poly bag. Checking on the use of group funds and preparation of minutes of work inspection results. The level of participation and the specified score consisted of high (4), moderate (2-3) and low 1.

d. Participation in the Planning Stage for KBR Seedling Planting

Participation in the socialization of planting seeds in KBR program covers, determining the location of planting, determining the area of planting, determining the community groups involved. The level of participation and score in the preparation stage of the plan for planting KBR seedlings as a result of the work consisted of high (4), moderate (2-3) and low (1).

e. Participation in the Implementation Phase of KBR Seedling Planting

Participation in planting activities consisted of cleaning up locations, making plant paths, making planting holes, making stakes, distributing seeds to planting holes, planting seeds, maintaining and replanting. The level of participation and score for the stage of planting in the KBR seedling planting activities consisted of high (5-7), moderate (3-4) and low (1-2).

\section{f. Participation in the Implementation Phase of the KBR Seed Planting Evaluation}

The evaluation of KBR activities consisted of technical guidance on plant evaluation, planting assessment, recapitulation of assessment results data, preparation of avaluation minutes. The level of participation and score in the implementation stage of evaluating KBR seedlings consisted of high (4), moderate (2-3) and low (1).

\section{2). Community Perception of the Implementation of the KBR Program}

Public perception of the implementation of the KBR program consisted of several aspects namely, knowledge and skills in managing KBR, environmental sustainability, and community welfare. Indicators and respondents' scores on community perceptions in making KBR consisted of high (3), moderate (2) and low (1).

3). Level of Community Participation in the KBR Program

The level of community participation in the KBR program were indicated by all phases of activity or the accumulation of score indexes in the planning, implementation, planting and evaluation / assessment stages consisting of high (25-36), moderate (13-24) and low (1-12).

\section{Discussion}

\subsection{Community, Role, Intensity and Participation Level of the KBR Program}

The total respondents was 31 individuals, used as a sample to answer the objectives of this study. The characteristics of each respondent in question are shown in Tables 1 and 2.

Table 1. Amount and percentage $(\%)$ of respondents based on ethnic origin and gender of KBR program participants

\begin{tabular}{|c|c|c|c|c|c|c|}
\hline \multirow{2}{*}{ Etnic Source } & \multicolumn{2}{|c|}{ Woman } & \multicolumn{2}{|c|}{ Man } & \multicolumn{2}{|c|}{ Amount } \\
\hline & $\sum$ & $\%$ & $\sum$ & $\%$ & $\sum$ & $\%$ \\
\hline Arfak & 5 & 16.13 & 7 & 22.58 & 12 & 38.71 \\
\hline Biak & 4 & 12.90 & 7 & 22.58 & 11 & 35.48 \\
\hline Kei & & & 1 & 3.23 & 1 & 3.23 \\
\hline Nabire & 1 & 3.23 & & & 1 & 3.23 \\
\hline Sanger (Manado) & & & 2 & 6.45 & 2 & 6.45 \\
\hline Serui & 3 & 9.68 & & & 3 & 9.68 \\
\hline Wasior & 1 & 3.23 & & & 1 & 3.23 \\
\hline Amount & 14 & 45.16 & 17 & 54.84 & 31 & 100.00 \\
\hline
\end{tabular}


Data from the analysis showed that males are most likely to participate in the KBR program and participants of the program are dominated by the indigenous people of Manokwari particularly, the Arfak tribe and other several Papua tribes.

Table 2. Number and percentage $(\%)$ of community participation by main job type and age group in KBR program activities

\begin{tabular}{|c|c|c|c|c|c|c|c|c|c|c|}
\hline \multirow{3}{*}{$\begin{array}{l}\text { Occupation } \\
\text { Main }\end{array}$} & \multicolumn{8}{|c|}{ Age Group (Years) } & \multirow{2}{*}{\multicolumn{2}{|c|}{ Amount }} \\
\hline & \multicolumn{2}{|c|}{$20-24$} & \multicolumn{2}{|c|}{$25-30$} & \multicolumn{2}{|c|}{$31-34$} & \multicolumn{2}{|c|}{$>34$} & & \\
\hline & $\sum$ & $\%$ & $\sum$ & $\%$ & $\sum$ & $\%$ & $\sum$ & $\%$ & $\sum$ & $\%$ \\
\hline Housewife & & 0.00 & 6 & 19.01 & 1 & 3.48 & 1 & 4.47 & 8 & 26.96 \\
\hline Unemployment & & 0.00 & 3 & 8.07 & 3 & 10.31 & 1 & 3.23 & 7 & 21.61 \\
\hline Honorary & & 0.00 & & 0.00 & 1 & 2.73 & 2 & 7.95 & 3 & 10.68 \\
\hline Student & 3 & 9.81 & & 0.00 & & 0.00 & & 0.00 & 3 & 9.81 \\
\hline State officer & & 0.00 & & 0.00 & 1 & 2.73 & 2 & 5.09 & 3 & 7.83 \\
\hline Farmer & & 0.00 & 1 & 3.48 & & 0.00 & 1 & 3.35 & 2 & 6.83 \\
\hline Private & & 0.00 & & 0.00 & 2 & 6.71 & & 0.00 & 2 & 6.71 \\
\hline Nurse & & 0.00 & & 0.00 & 1 & 2.86 & 1 & 2.61 & 2 & 5.47 \\
\hline Village Secretary & & 0.00 & & 0.00 & & 0.00 & 1 & 4.10 & 1 & 4.10 \\
\hline Amount & 3 & 9.81 & 10 & 30.56 & 9 & 28.82 & 9 & 30.81 & 31 & 100.00 \\
\hline
\end{tabular}

The age of KBR participants starts from 20 years to 40 years which isdivided into four age groups. The groups are classified into 9 main occupations dominated by housewives in the 25-30 years age group, students in the 20-24 years age group, the community without a permanent job in the 24-30 age group, and the general age group 31-34 with a proportion of around 9\%. It also included people who work for government agencies as civil servants, paramedics, village secretaries and honorary employees.

\subsection{Community Participation in the KBR Program}

Table 3. Percentage (\%) of community participation and level of participation in KBR program activities

\begin{tabular}{lccccccc}
\hline & \multicolumn{9}{c}{ Community Participation in the KBR Program } & Public Participation \\
\cline { 2 - 8 } Score & 1 & 2 & 3 & 4 & 5 & 6 & rate (\%) \\
\hline High (25-36) & $(\%)$ & $(\%)$ & $(\%)$ & $(\%)$ & $(\%)$ & $(\%)$ & 58.06 \\
Medium (13-24) & 12.90 & 51.61 & 32.26 & 77.42 & 100.00 & 19.35 & 41.94 \\
Low (1-12) & 3.23 & 48.39 & 51.61 & 22.58 & 0.00 & 54.84 & 0.00 \\
\hline
\end{tabular}

Note. 1. Planning, 2. Implementation, 3. Inspection, 4. Arrangement of Planting Plan, 5.Planting, 6. Planting Evaluation.

Based on the analysis, it was acknowledged that the community in the two villages participated in the whole KBR activities. This was appeared from the level of participation, which $100 \%$ of community participated in the program.58\% of the total community showed a high level of participation and about $41.94 \%$ of the people belong to the moderate level of participation. If we saw in detail, it was found not all communities were actively involved in the six stages of KBR activities, as described below.

\section{a. Planning Stage Participation}

The proportion of people involved in this planning stage was still relatively low, with only $67.74 \%$ participating in the formation of community groups. Different conditions in the four other activities, namely the socialization of the KBR program and the preparation of proposed activity was only $41.94 \%$, while for the activities of preparing proposals for group activities and cooperation agreements each only reached $12.90 \%$ and $16.13 \%$, respectively.

b. Participation in the KBR Program Implementation Stage

Not all communities actively participated in all activities and there were only six activities involving more than $50 \%$ of the community namely nameplate $(96.77 \%)$, sowing beds $(80.65 \%)$, seed / cuttings procurement $(100 \%)$, seed sowing (96.77\%), seeding $(61.29 \%)$, replanting plants $(96.77 \%)$ and cleaning grass / reeds / weeds $(100 \%)$. 
In the other six activities, community involvement was still low, namely below $50 \%$, namely weaving beds (35.48\%), fertilizer (45.16\%), seed weaning (32.26\%), fertilizing seedlings (25.81\%) and pest control (45.16\%).

\section{c. Participation Stage of Examination of the Results of Work Making KBR}

The percentage of people who participated in the activity above $80 \%$. The examination of the use of group funds was around $96.77 \%$, while the phase I and phase II examination activities involve $83.87 \%$ and $80.65 \%$ for each of these activities, respectively. In the activity of making minutes of group inspection only $32.26 \%$ of the participated community.

\section{d. Participation in the Planning Stage for KBR Seedling Planting}

The participation of communities in the four activities of this stage were shown with a value of the percentage of involvement. Above $50 \%$ of the community fully participated in the activities of determining the area of planting and determining the planting group with a value of $100 \%$ involvement percentage. In the socialization activities of KBR seedlings planting there was $77.42 \%$ of the people actively participating in the planting location determination activity at $96.77 \%$.

e. Participation in the Implementation Phase of KBR Seedling Planting

At the implementation stage of KBR seedlings the community actively participates in the seven activities at this stage as well as the KBR activities at the previous stage.

\section{f. Participation in the Implementation Phase of the KBR Seed Planting Evaluation}

Not all communities actively participate at this stage, it was indicated that the percentage of participation was below 50\%. The implementation of evaluation based on the technical guidance was $61.29 \%$. The KBR plant evaluation was $70.97 \%$ and the activity of calculating the results of the plant evaluation was $77.42 \%$. For the activities of making the minutes of this evaluation, only $19.35 \%$ of the participating communities were involved.

Generally, the study observed that not all members of the KBR group were actively participated in the stages in the KBR program. Particularly, in the stages of planning, implementing and evaluation of planting activities, community involvement was still very low. The condition was allegedly due to the lack understanding of the community related to the objectives of these activities. This was different from the technical activities in the field such as the preparation of planting plans and the implementation of planting that was able to involve almost all members of the KBR group.

The lack involvement of the community in the socialization activities of the KBR program has impacted to missunderstanding the next process at this planning stage such as the preparation of activity proposals, preparation of proposals for group activities (RUKK) and cooperation agreements in implementing the KBR program.

At the implementation stage of the KBR program, only half of the number of stages in this section involved the farmers' groups. Most of the participants did not work as farmers or hadnothing to do with planting activities. This was thought to cause only activities such as nameplate making, sowing beds, procurement and sowing of seeds, replanting and cleaning the beds, followed by almost all members. Different things were shown in activities that required technical knowledge such as fertilizer production, fertilizing seedlings and controlling pest and disease, not much followed by all members of KBR participants.

The situation also occuredat the stage of managing KBR where only three activities could involve around more than $80 \%$ of the members who actively participated in the activity. However, in the event of making minutes of group inspection, only $32 \%$ of the participants participated. It was estimated that this type of activity was administrative, so that not all communities (around $70 \%$ of the participant members) know how to complete this activity. In fact, the provisions and technical instructions in the activity of making the minutes had been submitted to the KBR program socialization activities at the beginning of its implementation.

The preparation stage of KBR seedlings was followed by almost all members of the KBR program participants. Similarly, in the implementation of KBR seedlings planting, all KBR program participants had shown full participation. At the time of the socialization of KBR program already involved more than $50 \%$ of participants. Furthermore, the determination of the location and area for planting as well as the determination of the KBR seedling planting group has involved almost all members of the KBR program participants. This condition was supported by community perceptions which provided the view that all communities agree with this KBR activity that would support forest sustainability. Therefore, these thoughts and perspectives motivate all members to be directly involved in determining locations that were in line with one of the objectives of the KBR program, namely to rehabilitate critical land. 
The involvement of community leaders in this activity played an important role where the community leaders are considered asrole models of the community. Besides, the community leaders are able to directly influence the mindset of the community. These factors cause the community with full awareness of the importance of planting these seeds in improving the condition of the land around the community that had been deemed damaged or critical. In addition, incentives in the form of wages thorugh this activity were also a driving factor that allowed the community to actively involve and engage in this activity. Juhaari and Atmanti (2009) state that incentives in the form of additional income is a trigger in increasing productivity in forestry activities. According to Sinery and Manusawai (2016), generally the level of community participation is high in activities that provides direct economic benefits through wages. This condition is a double benefit for the people who participated in the KBR program where the ecological benefits through land restoration and economic benefits for the KBR program. Participants receive incentives as additional income. The situation was foundin the KBR seedlings planting activities, the community could immediately receive incentives.

In the evaluation stage of KBR seed planting, not all community members of the KBR program could actively participate. This could be proven by planting evaluation minutes only $20 \%$ of the KBR program participants. In this activity, administrative and calculation knowledge was needed to complete this activity. This has become a factor influencing the participation of KBR program participants. On the other hand, it was possible that some people did not fully understand the procedures and objectives of the activity.

\section{1). Community Perception of the Implementation of the KBR Program}

The measurement of community perception in the implementation of the KBR program was using three indicators, knowledge and skills in making KBR, environmental sustainability, and community welfare. Furthermore, during the interview the community was asked to provide a view of the three indicators by giving one of three views, which is strongly agree, agree and disagree.

Table 4. Percentage (\%) of community perceptions of the implementation of the KBR program

\begin{tabular}{lccc}
\hline & \multicolumn{3}{c}{ Public Perceptions of the Implementation of the KBR Program } \\
\cline { 2 - 4 } & Knowledge and skills in making KBR & Environmental sustainability aspects & Social welfare aspects \\
\hline Strongly agree & 19.35 & 16.13 & 9.68 \\
Agree & 80.65 & 83.87 & 90.32 \\
Disagree & 0.00 & 0.00 & 0.00 \\
\hline
\end{tabular}

Most of the community agreed withthe implementation of the KBR program and hoped that this program would continue on an on going basis. Around $19.35 \%$ of the respondents strongly agreed to the KBR program which aimed to increase their knowledge and skills in managing KBR. About $16.13 \%$ of the public expressed that they strongly agreed that the KBR program was aimed at preserving the environment and around $9.68 \%$ of the community who stated that the KBR program was able to provide community welfare. The community in general approved the KBR program which was able to provide knowledge and skills in managing KBR (around $80.65 \%$ ), environmental aspects (around 83.87\%) and aspects of community welfare (around 90.32\%).

\subsection{Factors That Influence the Level of Community Participation}

In this study, respondents were asked the factors that influence their participation in KBR program. There were four factors identified in the field namely the lack of assistant and information regarding the KBR activities, the type of work currently more flexible, the involvement of community leaders, and the appropriate incentives of the program. The result revelaed that the involvement of community leaders and the appropriate incentives became the two main factors that cause community participation in the KBR program. The other factor involved was the assistant from the executor staffs, whichwas only given by around $32 \%$ of the community. The minor factor causing community involvement in the KBR program was that the type of work, which was about $6 \%$ of the community answering the factor.

Based on the interview, the community already hadthe awareness that the KBR program would provide ecological benefits, which both direct and indirect benefits to their lands in the next few years. Direct benefits, mean the results of planted crops could be directly utilizedby the community in which species planted were multipurpose trees species (MPTs) and also indirect benefits were in the form of ecosystem services in terms of controlling erosion, increasing the quality of water catchments, as a place live off animals and more. 


\section{Conclusion}

The level of community participation in the KBR program was included in the high category for the whole set of activities in the KBR. However, for activities related to technical knowledge on planting and administration, the participationof community was consideredrelatively low.

The primary factor affects the implementation of the KBR program was the direct involvement of community leaders. It played a significant role in motivating and encouraging the community to actively participate in the KBR program. In addition, the existence of financial considerations (incentives) among the community was one of the factors which determinethe community to actively participate inthe KBR program.

\section{Acknowledgements}

The authors wishes local community in Wasai Village, Arfai I Village and Environmental Research Centar of Papua University assisted during field data collection. Special thanks is also extended to those who contributed to the research and writing of this article.

\section{References}

Ditha, T. H., Suprijanto, \& Marijati, S. S. (2012). Factors Influencing Community Participation in Community Seedlings. Postgraduate Study Program of Natural Resources and Environmental Management at Lambung Mangkurat University, Banjarbaru.

Fitriadi, F., Gunawan, T., \& Rijanta, R. (2005). The Role of Government and Community Participation in Mangrove Forest Rehabilitation: Cases in Pemangkat District, Sambas Regency, West Kalimantan (Government Roles and Community Participation in the Rehabilitation of Mangrove Forest: A Case of Pemangkat Sub). Journal of Humans and the Environment, 12(3), 122-129.

Hasnawati. (1987). Problems of Community Participation in the Development of Sugar Factory Areas (Thesis). IPB Postgraduate Program, Bogor.

Hubeis, A. V. S. (1989). Community Participation in Development. LPPM IPB, Bogor.

Juhaari, I., \& Atmanti, H. D. (2009). Impact of Wage Changes on Output and Employment Opportunities in Manufacturing Industries in Central Java. TRACE: Journal of Economics and Policy, 2(2).

Ministry of Environmental dan Forestry. (2016). Guidelines for Implementing Community Nursery Plantation.

Protected Forest and Watershed Management Institution of Remu Ransiki. (2017). Forestry Statistics 2016. BPDASHL Remu Ransiki. Manokwari.

Sallatang, M. A. (1987). Factors That Hinder Community Participation in Development in Central Sulawesi. Hasanuddin University Research Institute, Makassar.

Sinery, A., \& Manusawai, J. (2016). Local Community Participation in the Management of Wosi Rendani Protection Forest. Journal of Humans and the Environment, 23(3), 394-401.

Statistics Central Agency of Manokwari. (2016). South Manokwari District in Figures. Manokwari: Central Statistics Agency, Manokwari.

Sugiyono. (2014). Statistics for Research. Bandung: Alfabeta Publisher.

Utama, S., Sumardjo, S., Susanto, D., \& Gani, D. S. (2015). The Dynamics of Forest Farmer Groups in the Management of Collaborative Production Forests in Perum Perhutani Unit I of Central Java Province. Journal of Counseling, 6(1).

\section{Copyrights}

Copyright for this article is retained by the author(s), with first publication rights granted to the journal.

This is an open-access article distributed under the terms and conditions of the Creative Commons Attribution license (http://creativecommons.org/licenses/by/4.0/). 